\title{
Improved Method for Calibration and Nonlinearity Correction of Microwave Power Sensor
}

\author{
Predrag RAKONJAC*, Zoran MITROVIĆ, Ivica MILANOVIĆ, Veljko NIKOLIĆ, Zoran ILIĆ, Nenko BRKLJAČ
}

\begin{abstract}
Power sensor nonlinearity contributes significantly to the increase of the microwave power measurement uncertainty. Current methods for sensor calibration do not provide correction of the results, due to the sensor nonlinearity. The paper describes an improved method and an automated measuring system based on it for power sensor calibration that enables the correction of the results, taking into account amplitude and frequency dependent nonlinearity. The novel calibration method is based on the application of high-linearity thermistor power transfer standard. The power sensor calibration process is fully automated and improved by applying the automated measuring system, PC and VEEpro software. Performed calculation of the calibration measurement uncertainty and the analysis of power measurement uncertainty budget indicate that the new calibration method allows the correction of sensor nonlinearity and contributes to significant reduction of the microwave power measurement uncertainty, ranging from $15,8 \%$ to $40,5 \%$. Experimental results and validation confirm the applicability of the improved calibration method and prove the existence of significant dependence of sensor nonlinearity on the power level, but also on the frequency of the measured microwave power.
\end{abstract}

Keywords: calibration factor; microwave power; measurement uncertainty; nonlinearity correction; power sensor calibration; power sensor nonlinearity

\section{INTRODUCTION}

Microwave power is one of the basic quantities in microwave technology, and microwave power meters with power sensors are among the most important measuring instruments in the microwave calibration laboratories and in the field of telecommunications and microwave technology [1-3]. Having that in mind, the calibration procedure of microwave power sensors, analysis of the uncertainty of calibration and uncertainty of power measurement must be considered closely.

The basic characteristic of the microwave power sensors, which is determined during calibration, is frequency dependence of the calibration factor $K$ of the sensor $[1,2,4,5]$. There are a number of methods and techniques for determining the calibration factor, which are described in detail in the literature [1,6-8]. Today, in many calibration laboratories the direct comparison transfer method with coaxial two-resistor power splitter is applied $[1,6,9,10]$. Also, the technique of the microwave power transfer standard (or Feed through microwave power standard) is used as a separate type of the direct comparison transfer method $[6,11]$.

Based on the analysis parameters of the measurement uncertainty budget of microwave power measurement using a power meter with power sensors, it can be inferred that the sensor nonlinearity is among the parameters contributing the most to the uncertainty of power measurement [2, 12]. In some cases, the measurement uncertainty due to the sensor nonlinearity has the greatest contribution to the uncertainty of microwave power measurement. Currently, sensor nonlinearity is considered as a fixed, declared sensor characteristic that is not subject to verification in the standard procedure of a sensor calibration process and there is no possibility of additional sensor nonlinearity correction after calibration. Sensor nonlinearity value is given as technical data and is of significance only in the power measurement uncertainty budget.

Using contemporary types of microwave power sensors, with extended dynamic range of power measurements (up to $90 \mathrm{~dB}$ ) and smart sensors with embedded EPROM memory (which contains calibration data, temperature and nonlinearity correction, etc.), sensor nonlinearity becomes an important issue $[5,13]$.

Power sensor nonlinearity can be from $0,1 \%$ (for thermistor standard sensor) to as high as $10 \%$ (for diode sensor) $[11,12]$ and contributes significantly to the uncertainty of power measurement. The issue of sensor nonlinearity measurement and correction and reexamination of the current method for sensor calibration is imposed as necessary and technically justifiable. The current methods for power sensor calibration and technical documentation do not allow for results correction due to sensor nonlinearity and thus reduction of power measurement uncertainty $[1,2,5,6,8,10]$. The existing practice has considered only sensor nonlinearity versus power level, while frequency dependence was disregarded and attributed to overall power measurement uncertainty. The literature provides scarce data on the power sensor nonlinearity frequency dependence. The current methods for sensor nonlinearity measurements are not realized within the standard power sensor calibration procedure but are performed separately only at one of the sensor working frequencies, disregarding the frequency dependence, and therefore there are no data necessary for full results correction due to nonlinearity.

The literature reports several methods for power sensor nonlinearity measurement: calibrated step attenuator method $[5,13,14]$, repeatable power step method [3, 15-17], direct comparison method with thermistor standard $[14,15]$ and application of the vector network analyzer (VNA) [14]. The listed procedures for nonlinearity measurement are very complex to realize and time-consuming and therefore they have been accomplished only at one working frequency of the sensor. In this way, nonlinearity frequency dependence is disregarded, therefore full nonlinearity correction cannot be done, and nonlinearity measurement is not a constituent part of the power sensor calibration.

To avoid the use of costly additional equipment, complicated methods and very demanding precise stepattenuator calibration, a novel integrated procedure for determining the calibration factor $K$ of power sensor and sensor nonlinearity measurement has been developed in the Technical Test Center (TTC) calibration laboratory and 
applied in this paper. The improved standard method for sensor calibration was realized through the application of a high-linearity thermistor microwave power transfer standard (with nonlinearity $<0,1 \%$ ) and customs of tware application for measurement process automation. Due to their structure, thermistor sensors always work under conditions of constant power applied to the sensor, which allows sensors' virtual independence of nonlinearity error $(<0,1 \%)[3,5,11]$. This feature allows the thermistor transfer standard to be applied to measure the unknown power sensor nonlinearity and calibrate the power sensor.

This paper presents an improved method and an automated measuring system for microwave power sensor calibration, which enables determination of power sensor calibration factors at several power levels, across the entire frequency range, and at the same time measures sensor nonlinearity and allows for results correction, due to nonlinearity. The analysis of measurement uncertainty in sensor calibration by applying this new method and power measurement uncertainty after nonlinearity correction indicates a significant reduction of power measurement uncertainty and significant improvement in the measurement characteristics of existing power sensors, without any sensors upgrade.

\section{POWER SENSOR CALIBRATION APPLYING MICROWAVE POWER TRANSFER STANDARD}

Fig. 1 shows a block diagram of power sensor calibration applying the microwave power transfer standard; it is the basic method in the TTC laboratory. The microwave power transfer standard shown in Fig. 1 consists of high-quality two-resistor power splitter, with a low-value reflection coefficient, and a temperaturestabilized thermistor monitoring sensor $(I)$ that is hardconnected to the port 3 of the power splitter [11]. A port 2 of the power splitter is the test port and the standard $(S)$ or the unknown-sensor DUT $(U)$ are alternately connected to it in the calibration process. The microwave power source is connected to the input port of the splitter 1. In this paper, calibration of the transfer standard was previously carried out in the external accredited calibration laboratory and the calibration factor of the transfer standard $K_{I}$ and the $S$ parameters of the power splitter $S_{i j}$ were determined.

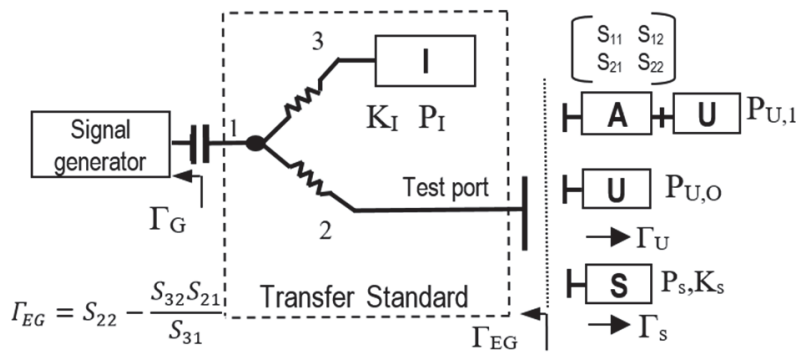

Figure 1 Power sensor calibration based on the power transfer standard

The power transfer standard is used to transfer the calibration factor $K_{I}$ from the transfer standard to the unknown sensor DUT $(U)$. According to the measurement configuration in Fig. 1, the unknown sensor $(U)$ is connected to the measuring port, and the calibration factor $K_{U}$ of the DUT sensor is determined using Eq. (1) [7, 11]:
$K_{U}=K_{I} \frac{P_{U}}{P_{I}}\left|1-\Gamma_{E G} \Gamma_{U}\right|=K_{I} \frac{P_{U}}{P_{I}} M_{U}$

In Eq. (1): $P_{U}$ is power measured using the unknown sensor $(U)$ and a corresponding power meter, $P_{I}$ is power measured using the transfer standard (I) with a corresponding power meter, $K_{I}$ is the calibration factor of the transfer standard determined in advance, during calibration, $\Gamma_{U}$ is the value of the reflection coefficients measured for the unknown sensor $(U)$, and $\Gamma_{E G}$ is the equivalent reflection coefficient obtained during calibration of the transfer standard. Applying Eq. (1) and known calibration factors $K_{I}$ of the transfer standard and measuring the ratio between power values $P_{U} / P_{I}$, the calibration factor $K_{U}$ of the unknown sensor is obtained. Calibration is done for one power level (e.g. $0 \mathrm{dBm}$ ) for all frequencies of interest. Part of Eq. (1) $M_{U}=\left|1-\Gamma_{E G} \Gamma_{U}\right|^{2}$ is a mismatch factor and represents a cause of uncertainty due to mismatch between the transfer standard and the unknown sensor $(U)$. The calibration method applied in this paper does not perform correction due to mismatch and the value $M_{U}=1$ was assumed in calculation (1), while real value of the mismatch $M_{U}$ is considered in the measurement uncertainty budget, Tab. 1 .

\subsection{Improved Method for Power Sensor Calibration and Nonlinearity Measurement}

Deviation of the sensor real response function $R_{U}(P)$ from the ideal linear response function $R_{S}(P)$ represents sensor nonlinearity (Fig. 2) [3, 13-16].

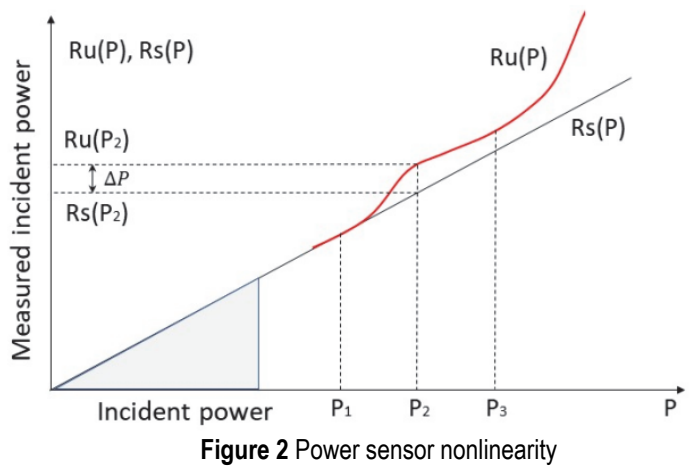

Based on the literature studied [13-16] and research conducted in this paper, power sensor nonlinearity $\left(N_{L}\right)$ can be also defined as a relative difference between responses of two sensors, i.e. a relative difference between the measured incident power of the unknown sensor $R_{U}(P)$ and the measured incident power of the ideal or standard sensor $R_{S}(P)$, for an observed incident power level $P$ on the sensor (Fig. 2). Sensor nonlinearity $\left(N_{L}\right)$ is then defined by Eq. (2):

$N_{L}(P)=\frac{R_{U}(P)-R_{S}(P)}{R_{U}(P)} \cdot 100 \%$

In Eq. (2): $R_{U}=P_{m U} / K_{U}$ and $R_{S}=P_{m S} / K_{S}$, where $R_{U}, R_{S}$ are the incident power values measured with the unknown and standard sensor, $P_{m U}, P_{m S}$ are readouts of unknown and standard sensor, and $K_{U}, K_{S}$ are calibration factors of the 
unknown and standard sensors. All mentioned methods for sensor nonlinearity measurement in chapter 1 mainly define sensor nonlinearity expressed in $(\mathrm{dB})$. This research established and mathematically proved that nonlinearity presented in Eq. (2) and expressed in (\%) is equivalent to the terms in $(\mathrm{dB})$ in [14-17].

For the purpose of DUT sensor calibration and DUT nonlinearity determination, the basic calibration method is improved in the TTC laboratory. The improved procedure involves calibration at several different power levels and normalization of $K_{U}$ to $K_{U, R}$, i.e. previously determined values of the calibration factor $K_{U}$, measured at different power levels, are divided by a calibration factor value at a chosen reference power level $K_{U, R}$ [18]. If the reference measurement and calibration are performed without an additional attenuator, according to Eq. (1), normalized calibration factor $K_{U, N}$ is defined by Eq. (3):

$K_{U, N}=\frac{K_{U}}{K_{U, R}}=\frac{P_{U}}{P_{I}} \frac{P_{I, R}}{P_{U, R}}$

In Eq. (3) index $R$ represents measurements conducted at the reference power level (in this paper the assumed reference power level is $P_{\text {ref }}=0 \mathrm{dBm}$ ), whereas for the quantities without index $R$ the measurements were carried out at other different power levels.

Throughout this research in our laboratory, it was noticed and mathematically proved that normalized calibration factor $K_{U, N}$ represents the sensor linearity, while the sensor nonlinearity $N_{L}$ defined based on Eq. (2) can be then expressed in terms of calculation via $K_{U, N}$, $N_{L}=\left(K_{U, N}-1\right)$ and is defined by the derived new Eq. (4):

$N_{L}=\left(K_{U, N}-1\right) \cdot 100 \%=\left(\frac{K_{U}}{K_{U, R}}-1\right) \cdot 100 \%$

Based on above mentioned, nonlinearity of the sensor $N_{L}$ is determined by calculation as a relationship between previously measured calibration factors $K_{U}$ of the sensor at several power levels and the reference calibration factors $K_{U, R}$ (for reference power level $P_{\text {ref }}=0 \mathrm{dBm}$ ) and by applying Eq. (4). Practically, by applying an improved calibration method, sensor nonlinearity (versus frequency and power level) is obtained mathematically without additional complex measurements and demanding measurement configurations.

However, measuring range of the applied thermistor power transfer standard is relatively small (from $-20 \mathrm{dBm}$ to $14 \mathrm{dBm}$ ) and does not enable calibration of $K_{U}$ and nonlinearity below $-20 \mathrm{dBm}$. To increase the system calibration range below $-20 \mathrm{dBm}$, a fixed unknown attenuator was inserted between the measuring port and the DUT, Fig. 1. The calibration factor of DUT $K_{U}$ with an inserted attenuator is then defined by Eq. (5), [18]:

$K_{U}=K_{I} \frac{P_{U}}{P_{I}} \frac{\left|1-\Gamma_{E G} S_{11}-\Gamma_{U} S_{22}+\Gamma_{E G} \Gamma_{U} \Delta\right|^{2}}{\left|S_{21}\right|^{2}}$ where $\Delta=S_{11} S_{22}-S_{12} S_{21}$ and $S_{i j}$ are $S$-parameters of the attenuator. Since the transfer standard has high linearity, Eq. (1) and Eq. (5) can be utilized at any power level $P_{U}$ and $P_{I}$ if they fall within the dynamic range of the transfer standard sensor. It is thus possible to measure $K_{U}$ for different power levels, $K_{I}$ being calibrated only at one power level (a common level is $0 \mathrm{dBm}$ ). If reference measurement is conducted without the attenuator, according to Eq. (1), and calibration is done with the attenuator, applying Eq. (5), the relative calibration factor $K_{U, N}$ can be then defined using Eq. (6) [18]:

$$
\begin{aligned}
& K_{U, N}=\frac{K_{U}}{K_{U, R}}= \\
& =\frac{P_{U}}{P_{I}} \frac{P_{I, R}}{P_{U, R}} \frac{\left.{ }_{1-\Gamma_{E G} S_{11}-\Gamma_{U} S_{22}+\Gamma_{E G} \Gamma_{U} \Delta}\right|^{2}}{\left|S_{21}\right|^{2}\left|1-\Gamma_{E G} \Gamma_{U}\right|^{2}}= \\
& =\frac{P_{U}}{P_{I}} \frac{P_{I, R}}{P_{U, R}} A
\end{aligned}
$$

In Eq. (6) $A$ represents effective attenuation of the inserted "unknown attenuator". However, attenuation of the attenuator $A$ does not need to be determined in advance using some of the known methods for attenuator calibration [19]. The attenuation of $A$ can be determined by one additional measurement using the same measurement configuration as for calibration, Fig. 1. Since the transfer standard has high-linearity and dynamic range from $-20 \mathrm{dBm}$ to $14 \mathrm{dBm}, K_{U}$ can be measured with and without the attenuator by applying Eq. (5) and Eq. (1), with the power level $P_{U}$ on DUT kept approximately equal in both measurements. Two different equations will be yielded for $K_{U}$, which should be equal in value, due to retained approximately equal power level $P_{U}$ on the DUT. Eq. (1) and Eq. (5), it is possible to obtain the value of effective attenuation of the "unknown attenuator" $A$, according to Eq. (7), [18]:

$$
A=\frac{\left|1-\Gamma_{E G} S_{11}-\Gamma_{U} S_{22}+\Gamma_{E G} \Gamma_{U} \Delta\right|^{2}}{\left|S_{21}\right|^{2}\left|1-\Gamma_{E G} \Gamma_{U}\right|^{2}}=\frac{P_{U, 0}}{P_{I, 0}} \frac{P_{I, 1}}{P_{U, 1}}
$$

where subscripts 1 and 0 denote measured power values $P_{U}$ and $P_{I}$ realized with and without the attenuator. It should be highlighted that power values at DUT with and without the attenuator $\left(P_{U, 0}\right.$ and $\left.P_{U, 1}\right)$ in Eq. (7) should be kept as much as possible close to the same value. It is a prerequisite for applying Eq. (7), due to unknown linearity of DUT.

The $20 \mathrm{~dB}$ inserted attenuator was used in this paper. If values of the attenuator $A$ are determined according to Eq. (7), the value of the calibration factor $K_{U}$ of DUT, obtained with the attenuator, can be now expressed by Eq. (8):

$$
K_{U}=K_{I} \frac{P_{U}}{P_{I}} A\left|1-\Gamma_{E G} \Gamma_{U}\right|^{2}=K_{I} \frac{P_{U}}{P_{I}} A M_{U}
$$

In Eq. (8) $M_{U}$ is a mismatch factor and is defined within Eq. (1). Normalized calibration factor $K_{U, N}$ obtained 
by applying the attenuator $A$ is determined based on Eq. (6) using the values of $A$ defined according to Eq. (7), or as a relationship $K_{U} / K_{U, R}$ Eq. (6).

On the basis of applying high-linearity thermistor power transfer standard, "unknown attenuator" $A$, improved method and automated measuring system, it is possible to define the calibration factor $K_{U}$ at different power levels in the entire frequency range and thus determine DUT linearity. The DUT linearity corresponds to the normalized calibration factor $K_{U, N}$ and it is defined based on Eq. (6). According to this research, sensor nonlinearity $\left(N_{L}\right)$ can be then calculated using novel Eq. (4) also in the entire frequency range, without additional measurements (Fig. 6 and Fig. 7).
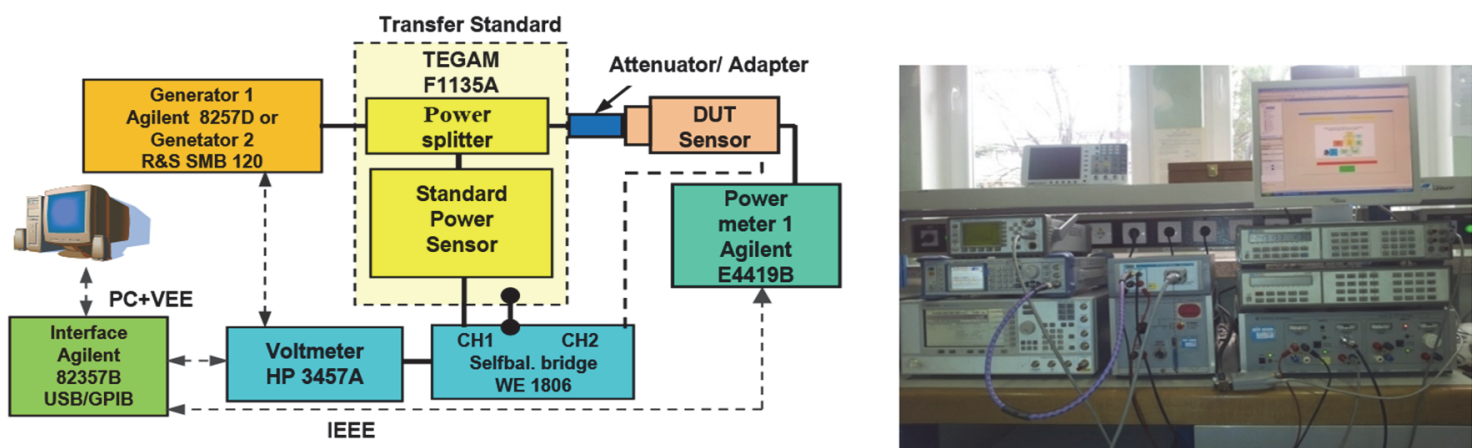

Figure 3 Block diagram and figure of the automated measuring system for power sensor calibration and nonlinearity measurement

\subsection{Power Sensor Calibration and Nonlinearity Correction}

During the procedure of DUT sensor calibration, the power measured on DUT sensor $R_{U}$ and the power on the standard sensor $R_{S}$ is equalized (i.e. $R_{U}=R_{S}$ ), and the DUT calibration factor $K_{U}$ is determined, Eq. (1) and Eq. (2). The power measured on DUT sensor $R_{U}$ equals the power on the thermistor transfer standard $R_{S}$ of high linearity $\left(N_{L}<0,1 \%\right)$. Using the mentioned condition (i.e. $R_{U}=R_{S}$ ), high linearity of the transfer standard, and Eq. (2) and Eq. (9), it can be proved that after calibration the DUT sensor nonlinearity equals zero $\left(N_{L}=0\right)$, for the power level of sensor calibration (for $P=P_{\text {cal }}$ ).

$$
N_{L}(P)=\frac{R_{U}(P)-R_{S}(P)}{R_{S}(P)}=\frac{0}{R_{S}(P)}=0 \text { for } P=P_{c a l}
$$

DUT sensor nonlinearity is corrected during the calibration procedure through determining $K_{U}$, for the power level at which calibration was carried out but also for approximate power levels. In accordance with the proposed method, by determining the calibration factors $K_{U}$ at several different power levels and by creating a family of curves of calibration factors $K_{U}$ (Fig. 4 and Fig. $5)$, it is possible to correct sensor nonlinearity in the entire measuring range. The thus determined calibration factors $K_{U}$ contain maximum correction of sensor nonlinearity, considering sensor nonlinearity dependence on the amplitude and frequency. By applying the family of curves and selecting the appropriate calibration factor $K_{U}$, for the approximate measured power level, it is possible to measure power level without impact of the sensor nonlinearity error. In this way, we can correct sensor nonlinearity and significantly reduce measurement uncertainty in measuring power with that sensor; for analysis refer to Tab. 5 and Fig. 8.

However, sensor nonlinearity is not completely eliminated, there still exists residual minor nonlinearity of the thermistor transfer standard $(<0,1 \%)$. But it is taken into account and considered in the analysis of calibration measurement uncertainty of DUT sensor, Tab. 1.

\section{AUTOMATED MEASURING SYSTEM OVERVIEW}

For the needs of microwave power sensor calibration in the TTC calibration laboratory an automated measuring system was developed, which enables calibration of thermistor, thermocouple and diode power sensors [20]. The Automated Measuring System (AMS) for power sensor calibration is based on the thermistor power transfer standard TEGAM F1135A, programmable instruments and the customs of tware application in Agilent VEEpro software [11, 20]. A block diagram and figure of the automated measuring system are shown in Fig. 3. Programmable instruments with GPIB interface are connected by Interface USB/GPIB to the PC computer with installed software Agilent VEEpro and customs of tware application, which controls the entire calibration process. The measuring range of the power transfer standard F1135A is declared of $-20 \mathrm{dBm}$ to $14 \mathrm{dBm}$, and frequency range of $10 \mathrm{MHz}$ to $26,5 \mathrm{GHz}$. However, experimental measurements in TTC found that maximum usable power measuring range is between $-15 \mathrm{dBm}$ and $13 \mathrm{dBm}$. The transfer standard nonlinearity is declared for $<0,1 \%$, and the power splitter insertion loss is from $6 \mathrm{~dB}$ to $10 \mathrm{~dB}$, depending on the frequency. The transfer standard calibration factor $\left(K_{I}\right)$ was previously determined in the external accredited calibration laboratory TEGAM with traceability to NIST and expanded measuring uncertainty $(k=2) \mathrm{U}$ of $1,15 \%$ to $2,34 \%$ for the calibration power level of $1 \mathrm{~mW}$, Tab. 3.

The power at the transfer standard $\left(P_{I}\right)$ is measured using a double self-balancing bridge $(\mathrm{CH} 1)$ and a $6 \frac{1}{2}$ digit resolution digital voltmeter [11]. The power on the unknown DUT thermocouple or diode sensor $\left(P_{U}\right)$ is measured with a power meter - 1 (4 - digits resolution), and if a thermistor sensor is calibrated, a second channel ( $\mathrm{CH} 2)$ of the self-balancing bridge and voltmeter is used. A microwave power source is generator - 1 (frequency from $250 \mathrm{kHz}$ to $26,5 \mathrm{GHz}$, power level from $-135 \mathrm{dBm}$ to $12 \mathrm{dBm}$ ) or generator - 2 (frequency from $100 \mathrm{kHz}$ to $20 \mathrm{GHz}$, power level from $-145 \mathrm{dBm}$ to $30 \mathrm{dBm}$ ). The application of generator - 1 and transfer standard (with 
$10 \mathrm{~dB}$ insertion loss for $26,5 \mathrm{GHz}$ ) enables power sensor calibration in the $10 \mathrm{MHz}$ to $26,5 \mathrm{GHz}$ frequency range, for power levels at DUT only from $-15 \mathrm{dBm}$ to $2 \mathrm{dBm}$. The application of generator - 2 allows calibration in the $10 \mathrm{MHz}$ to $20 \mathrm{GHz}$ frequency range but for higher power levels at DUT, from $-15 \mathrm{dBm}$ to $13 \mathrm{dBm}$. For power levels higher than $13 \mathrm{dBm}$ the calibration is technically impossible in the presented measurement configuration with hard-connection of the thermistor monitoring sensor (I) and the power splitter (Fig. 1, port 3). The unknown attenuator is used for calibration at DUT power levels below $-15 \mathrm{dBm}$, according to the method described in chapter 2.1. In this paper, the $20 \mathrm{~dB}$ fixed attenuator is applied, which enables calibration up to $-35 \mathrm{dBm}$ power level. The measuring system presented in Fig. 3 can be used for sensor calibration and nonlinearity correction for the maximum power levels from $-43 \mathrm{dBm}$ to $13 \mathrm{dBm}$.

The power sensor calibration process is fully automated and improved by using the PC and VEEpro software. The software is designed for instrument control, collecting measurement data, their processing, and a report generation. The software application has the following separate phases (modules):

Measurement configuration,

Zero set and Cal to Reference oscillator,

Power level control on DUT/Standard sensor,

DUT sensor calibration,

- Data processing and report generation.

In the Measurement configuration phase the basic data on DUTsensor is entered in the software (manufacturer, type, serial number, time, date) for the purpose of generating a calibration report.Specification is set for a desired power level of conducting sensor calibration, frequency of calibration performance (choice of predefined values or entry by choice), calibration factors of transfer standard $\left(K_{I}\right)$ from a calibration certificate, number of repeated measurements with disconnecting and connecting of DUT sensor connector, previously measured values of DUT reflection coefficient. If an adapter/attenuatoris used for DUT calibration, the values for adapter/attenuator attenuation are determined and entered in the software.

In the Zero set and Calphase the software performs DUT sensor zeroing (setting to "0") and depending on the type of DUT sensor (for thermocouple and diode sensors), setting DUT sensor to the reference source1 $\mathrm{mW}$.

In the Power level control phase the software defines generator output power levels to achieve the required stability of calibration power level on DUT or standard sensor. Stability of power level at the transfer standard, depending on frequency, is provided by software control, regulation of the generator output level and application of standard sensor. Power stability achieved at the measuring connector of the transfer standard is $\pm 0,02 \mathrm{~mW}$ across the entire frequency range. In determining the unknown attenuator the software maintains DUT sensor power level stability when measurements are performed with and without the attenuator (within limits $\pm 0,2 \mathrm{~dB}$ ).

During the DUT sensor calibration phase, DUT is connected to the transfer standard, specific $\mathrm{CW}$ power level is supplied, and alternating readings of power $P_{U}$ at DUT and power $P_{I}$ at the transfer standard are done. Readings of the power levels $P_{U}$ and $P_{I}$ for each frequency are done 10 times and values obtained are averaged and the standard deviation is calculated. Based on Eq. (1), calibration factors $\left(K_{U}\right)$ are calculated for the unknown DUT and data is uploaded in computer memory. Calibration is first done for one power level (e.g. $0 \mathrm{dBm}$ ) for the reference frequency of $50 \mathrm{MHz}$, and then it is repeated for all other frequencies of interest. Sensor calibration is performed at the following frequencies: $50 \mathrm{MHz}, 500 \mathrm{MHz}, 1 \mathrm{GHz}, 2,3, \ldots, 26 \mathrm{GHz}, 26,5 \mathrm{GHz}$, but this set of frequencies can be easily changed. For a single power level the entire calibration procedure is repeated at least 4 times, with disconnecting and connecting of DUT connector and results averaging.

In the Data processing and report generating phase the software using the collected data in the memory and entered initial parameters is calculating the final value of the calibration factor $\left(K_{\mathrm{DUT}}\right)$, calibration measurement uncertainty, and creates numerical and graphic reports on calibration. First, mean value of repeated measurements for calibration factor $\left(K_{U}\right)$ is calculated, due to the repeatability of connector connecting. For thermocouple and diode sensors the final result, the calibration factor $\left(K_{\mathrm{DUT}}\right)$ of DUT is shown relative to the reference calibration factor $\left(K_{r e f}\right)$ for $50 \mathrm{MHz}$, according to Eq. (10) [21]. Thereafter, the software calculates calibration measurement uncertainty for each frequency (according to Tab. 1). The final result of calibration (calibration report) yields a diagram (*.bmp file) and numerical values $(*$.txt file) of the calibration factor $\left(K_{\mathrm{DUT}}\right)$ of DUT for a specific power level and values of expanded measurement uncertainty $U$ for $K_{\text {DUT. }}$. Data is stored in computer memory and is suitable for further processing, analysis, and storage.

Calibration proceeds under controlled conditions at the temperature of $(23 \pm 1)^{\circ} \mathrm{C}$ and relative humidity of $(55 \pm 10) \%$.

After standard sensor calibration for the reference power level of $0 \mathrm{dBm}$, additional calibration is conducted at several different power levels in accordance with DUT measuring range and user needs (the improved method). For the power levels between $-15 \mathrm{dBm}$ and $13 \mathrm{dBm}$ the software program simply specifies desirable power level at DUT and the calibration process is identical with the procedure described above. This paper shows values for $(13,10,7,5,0,-5,-10) \mathrm{dBm}$ power levels.

For calibration on the power level at DUT below $-15 \mathrm{dBm}$, the $20 \mathrm{~dB}$ unknown attenuator was inserted between the DUT and the measuring connector of the transfer standard (chapter 2.1 and Fig. 1). As the transfer standard has sufficient dynamic range and high linearity, determination of $K_{U}$ was carried out at two different power levels at the transfer standard (for $P_{I, 1}$ and $P_{I, 0}$ ), with and without the attenuator, and the value of "unknown attenuator" was defined based on Eq. (7).

First, the described standard measurement of the calibration factors $K_{U}$ of DUT was carried out at the power level of $-10 \mathrm{dBm}$ without additional attenuator. This measurement determined the values of $K_{U, 0}$ for power levels $P_{U, 0} \approx-10 \mathrm{dBm}$ at DUT and incident power $P_{I, 0} \approx-10 \mathrm{dBm}$ at the standard sensor. Thereafter, additional measurement of the calibration factors $K_{U, 1}$ was performed with the inserted unknown attenuator in front of the DUT. The incident power level at the standard sensor $P_{I, 1} \approx 10 \mathrm{dBm}$ was adjusted with the power level control 
software module in such a way that the power level at DUT remained constant $P_{U, 1} \approx P_{U, 0} \approx-10 \mathrm{dBm}$ (within limits $\pm 0,2 \mathrm{~dB})$. Based on the measured values of power levels $\left(P_{I, 1}\right.$ and $\left.P_{I, 0}\right)$ and $\left(P_{U, 1}\right.$ and $\left.P_{U, 0}\right)$ with and without the attenuator and applying Eq. (7), values for the attenuation of the unknown attenuator $A$ were determined for all frequencies of interest. Furthermore, examples of power values readouts for determining the attenuator $A$ attenuation are given for the frequency of $18 \mathrm{GHz}$ : $P_{I, 1}=7,9788 \mathrm{~mW}, P_{I, 0}=0,0793 \mathrm{~mW}$ (power readouts), $P_{U, 1}=0,0939 \mathrm{~mW}, P_{U, 0}=0,0979 \mathrm{~mW}$. Based on Eq. (7), attenuation was defined for frequency of $18 \mathrm{GHz}$ : $A=104,8923$ (or $20,2074 \mathrm{~dB}$ ) with expanded measurement uncertainty $U=0,03 \%$ (for $k=2$ ). Other attenuation values of $A$, ranging from $50 \mathrm{MHz}$ to $18 \mathrm{GHz}$, were defined with measurement uncertainty $U($ for $k=2)$ in the range between $0,03 \%$ and $0,09 \%$.

The $20 \mathrm{~dB}$ attenuator thus defined is positioned in front of the DUT and used in combination with the transfer standard for sensor calibration at desired power levels, based on Eq. (8), which enables the expansion of the system measuring range for the power levels to $-35 \mathrm{dBm}$. The desired power level at DUT is previously software adjusted by applying the transfer standard and values of the attenuator $A$. Using power readout $P_{U}$ at DUT and power readout $P_{I}$ at the transfer standard, applying specific values of the attenuator $A$, Eq. (8) and the described procedure, the calibration was performed for power levels $(-10,-20,-30) \mathrm{dBm}$. Sensor calibration by applying the new method results in the family of curves of the calibration factors $\left(K_{U}\right)$ determined for different power levels $(13,10,7,5,0,-5,-10,-20,-30) \mathrm{dBm}$ (Fig. 4 and Fig. 5). On the basis of previously determined calibration factors $\left(K_{U}\right)$ for different power levels and Eq. (3) and Eq. (6), the normalized calibration factor $\left(K_{U, N}\right)$ is calculated, representing sensor linearity. The sensor nonlinearity is after that simply calculated using Eq. (4), (Fig. 6 and Fig. 7).

It should be highlighted that by applying the described new calibration procedure and automated measuring system, sensor calibration is simultaneously performed and sensor nonlinearity is determined, without use of additional equipment and time-consuming measurements. The application of an automated measuring system, PC and VEE software significantly simplifies and speeds up the calibration process, eliminates human error, enables steady control of the calibration process, simple storage and subsequent analysis of collected data.

\section{MEASUREMENT UNCERTAINTY}

For thermocouple and diode power sensors the calibration factor of DUT is shown relative to the reference calibration factor $\left(K_{r e f}\right)$ for the frequency of $50 \mathrm{MHz}$ [21].

The relative calibration factor $K_{U r e l}$ of DUT is defined in Eq. (10):

$$
K_{\text {Urel }}(f)=\frac{K_{U}(f)}{K_{\text {ref }}} K_{\text {DUT }}
$$

where $K_{\text {Urel }}(f)$ is the relative calibration factor for a specific frequency $f, K_{U}(f)$ is measured calibration factor at a given frequency $f$ Eq. (1) and Eq. (8) and $K_{r e f}$ is the reference calibration factor for the reference frequency of $50 \mathrm{MHz}$. To perform calculation of the relative calibration factor $K_{\text {DUT }}$ and measurement uncertainty analysis of thermocouple and diode power sensors, a mathematical model was defined, as shown in Eq. (11):

$$
K_{\mathrm{DUT}}=\frac{K_{I f}}{K_{\text {Iref }}} \delta_{C F} n_{l} R_{D} R_{I} p_{k} \frac{M_{U f}}{M_{U r e f}} \frac{A_{f}}{A_{\text {ref }}}+\sigma_{n}
$$

Table 1 Measurement uncertainty budget of the E4413A diode sensor calibration at $f=12 \mathrm{GHz}$, without attenuator for $13 \mathrm{dBm}(\mathrm{a})$ and with

\begin{tabular}{|c|c|c|c|c|c|}
\hline \multicolumn{6}{|c|}{ (1) } \\
\hline$X i$ & $x i$ & $u(x i) / \%$ & Dist/Type & $c i$ & $u_{i}(y) / \%$ \\
\hline$K_{I f}$ & 0,8441 & 0,72 & Normal/B & 1,2302 & 0,8858 \\
\hline$K_{\text {Iref }}$ & 0,9900 & 0,595 & Normal /B & $-1,0489$ & $-0,6241$ \\
\hline$\delta_{C F}$ & 1 & 0,2887 & Rectang./B & 1,0384 & 0,2998 \\
\hline$n_{l}$ & 1 & 0,05 & Normal /B & 1,0384 & 0,0519 \\
\hline$\delta_{I}$ & 1 & 0,0288 & Rectang./B & 1,0384 & 0,0299 \\
\hline$P_{U f}$ & 20,4988 & $\mathrm{~mW}$ & - & - & - \\
\hline$P_{\text {Uref }}$ & 19,7399 & $\mathrm{~mW}$ & - & - & - \\
\hline$R_{D}$ & 1,0384 & 0,02 & Normal/B & 1,0000 & 0,0200 \\
\hline$P_{\text {Iref }}$ & 19,6117 & $\mathrm{~mW}$ & - & - & - \\
\hline$P_{I f}$ & 16,7214 & $\mathrm{~mW}$ & - & - & - \\
\hline$R_{I}$ & 1,1728 & 0,00006 & Normal/B & 0,8854 & 0,0001 \\
\hline$M_{U f}$ & 1 & 0,0427 & Ushaped/B & 1,0384 & 0,0443 \\
\hline$M_{\text {Uref }}$ & 1 & 0,0092 & Ushaped/B & $-1,0384$ & $-0,0095$ \\
\hline$p_{k}$ & 1 & 0,1000 & Normal/A & 1,0384 & 0,1038 \\
\hline$\sigma_{n}$ & 0 & 0,0500 & Normal/A & 1,0000 & 0,0500 \\
\hline$K_{\text {DUT }}$ & $103,84 \%$ & \multicolumn{2}{|c|}{$\begin{array}{c}\text { Combined measurement } \\
\text { uncertainty }\end{array}$} & $u_{c}\left(K_{\mathrm{DUT}}\right)$ & 1,1328 \\
\hline \multicolumn{2}{|c|}{$\begin{array}{c}\text { For } 12 \mathrm{GHz}, \\
13 \mathrm{dBm}\end{array}$} & \multicolumn{2}{|c|}{$\begin{array}{c}\text { Expanded measurement } \\
\text { uncertainty }\end{array}$} & $U(k=2)$ & $2,27 \%$ \\
\hline
\end{tabular}
attenuator for $-30 \mathrm{dBm}(\mathrm{b})$

\begin{tabular}{|c|c|c|c|c|c|}
\hline$X i$ & $x i$ & $u(x i) / \%$ & Dist/Type & $c i$ & $u_{i}(y) / \%$ \\
\hline$K_{I f}$ & 0,8441 & 0,72 & Normal /B & 1,1829 & 0,8517 \\
\hline$K_{\text {Iref }}$ & 0,9900 & 0,595 & Normal/B & $-1,0085$ & $-0,6001$ \\
\hline$\delta_{C F}$ & 1 & 0,2887 & Rectang./B & 0,9985 & 0,2883 \\
\hline$n_{l}$ & 1 & 0,05 & Normal /B & 0,9985 & 0,0499 \\
\hline$\delta_{I}$ & 1 & 0,0288 & Rectang./B & 0,9985 & 0,0288 \\
\hline$P_{U f}$ & 0,0010 & $\mathrm{~mW}$ & - & - & - \\
\hline$P_{\text {Uref }}$ & 0,0011 & $\mathrm{~mW}$ & - & - & - \\
\hline$R_{D}$ & 0,8976 & 0,0408 & Normal/B & 1,1123 & 0,0454 \\
\hline$P_{\text {Iref }}$ & 0,0990 & $\mathrm{~mW}$ & - & - & - \\
\hline$P_{l f}$ & 0,0855 & $\mathrm{~mW}$ & - & - & - \\
\hline$R_{I}$ & 1,1573 & 0,0222 & Normal/B & 0,8627 & 0,0192 \\
\hline$A_{f}$ & 99,1133 & 0,0437 & Normal/B & 0,0101 & 0,0004 \\
\hline$A_{r e f}$ & 87,9238 & 0,0330 & Normal/B & $-0,0114$ & $-0,0004$ \\
\hline$M_{U f}$ & 1 & 0,0427 & Ushaped/B & 0,9985 & 0,0426 \\
\hline$M_{\text {Uref }}$ & 1 & 0,0092 & Ushaped/B & $-0,9985$ & $-0,0092$ \\
\hline$p_{k}$ & 1 & 0,1000 & Normal/A & 0,9985 & 0,0998 \\
\hline$\sigma_{n}$ & 0 & 0,0500 & Normal/A & 1,0000 & 0,0500 \\
\hline$K_{\text {DUT }}$ & $99,85 \%$ & & & $u_{c}\left(K_{\mathrm{DUT}}\right)$ & 1,0902 \\
\hline \multicolumn{3}{|c|}{$12 \mathrm{GHz},-30 \mathrm{dBm}$ with $\mathrm{A}$} & & $U(k=2)$ & $2,18 \%$ \\
\hline
\end{tabular}

\begin{tabular}{|l|l|l|l|l|}
\hline \multicolumn{5}{|c|}{ a) } \\
\hline
\end{tabular}


Eq. (11) includes all relevant quantities contributing to the sensor calibration process:

$K_{\text {DUT }}$ is the relative calibration factor of DUT for frequency $f$ expressed relative to $K_{r e f}$ (for $50 \mathrm{MHz}$ ) (10).

$K_{I f}$ and $K_{\text {Iref }}$ are calibration factor values of the transfer standard for frequency $f$ and reference frequency of $50 \mathrm{MHz}$ determined in the external calibration laboratory, values of the calibration factor and expanded measurement uncertainty $(k=2)$ shown in Tab. 3.

$\delta_{C F}$ encompasses all changes in the calibration factor values of the transfer standard since the last calibration, the calibration factor annual change declared for $\pm 0,5 \%$, the rectangular distribution is assumed, and the measurement uncertainty is type B.

$n_{l}$ is declared transfer standard nonlinearity, in the measuring range of transfer standard is $\pm 0,1 \%$, the normal distribution is assumed, uncertainty is type $\mathrm{B}$.

$R_{D}=P_{U f} / P_{\text {Uref }}$ is the ratio between measured power levels at DUT measured with a power meter - 1 for frequency $f$ and ref. frequency $(50 \mathrm{MHz})$. Measurement is performed in a short time interval using the same power meter, the same measurement configuration, and approximately the same power values are measured. Since the same power meter is used to measure both power levels $P_{U f}$ and $P_{\text {Uref }}$ at DUT at frequency $f$ and $50 \mathrm{MHz}$, their contributions to measurement uncertainty can be considered correlated, influencing the reduction of measurement uncertainty in the power levels' ratio measurement [22]. In this case, certain sources of measurement uncertainty can be disregarded (e.g. power meter accuracy in the power measurement, power reference source accuracy, accuracy of the calibration at the reference source, mismatch uncertainty of the calibration at the reference source) [2]. Considerations involved only uncertainty due to limited resolution of the power meter 4-digits resolution. Also, power meter uncertainty due to zero set, zero drift of sensor and measurement noise of the sensor were considered. All three mentioned sources of uncertainty are negligibly small compared to the uncertainty of power meter resolution and can be disregarded. The normal distribution is assumed, uncertainty is type $\mathrm{B}$.

$R_{I}=P_{\text {Iref }} / P_{I f}$ is the ratio between the measured power values at the transfer standard $P_{I}$ measured with a selfbalancing bridge and the multimeter for the frequencies of $50 \mathrm{MHz}$ and $f$. Measurement is conducted using the same self-balancing bridge and multimeter in a short time interval and the same measurement configuration, and approximately the same values of the power and DC voltage are measured. Since the same instrumentation is used to measure both power values at the transfer standard $P_{\text {Iref }}$ and $P_{I f}$ at the frequencies of $50 \mathrm{MHz}$ and $f$, their contribution to measurement uncertainty can be considered as correlated, which contributes to the reduction of measurement uncertainty in DC voltage ratio measurement. In this case, specific sources of measurement uncertainty can be disregarded (selfbalancing bridge accuracy which is negligibly small, multimeter DC voltage accuracy), so that we can consider only the uncertainty due to multimeter limited resolution of $6 \frac{1}{2}$ digits for the measuring range of $3 \mathrm{Vdc}$ [22]. The normal distribution is assumed, uncertainty is type B.

Table 2 Summary of measured values of the Calibration factor KDUT and expanded measurement uncertainty U for the E4413A diode sensor determined in TTC

\begin{tabular}{|c|c|c|c|c|c|c|c|c|c|c|}
\hline \multirow{3}{*}{$\begin{array}{c}\text { Power level } \\
\mathrm{dBm}\end{array}$} & \multicolumn{10}{|c|}{ Calibration factor $K_{D U T}$ and expanded measurement uncertainty $U($ for $k=2)$} \\
\hline & \multicolumn{2}{|c|}{$50 \mathrm{MHz}$} & \multicolumn{2}{|c|}{$2 \mathrm{GHz}$} & \multicolumn{2}{|c|}{$6 \mathrm{GHz}$} & \multicolumn{2}{|c|}{$12 \mathrm{GHz}$} & \multicolumn{2}{|c|}{$18 \mathrm{GHz}$} \\
\hline & $K_{\text {DUT }} / \%$ & $U / \%$ & $K_{\text {DUT }} / \%$ & $U / \%$ & $K_{\text {DUT }} / \%$ & $U / \%$ & $K_{\text {DUT }} / \%$ & $U / \%$ & $K_{\text {DUT }} / \%$ & $U / \%$ \\
\hline 13 & 100 & 0,63 & 106,33 & 1,96 & 104,39 & 2,03 & 103,84 & 2,27 & 102,12 & 2,73 \\
\hline 0 & 100 & 0,62 & 102,19 & 1,88 & 101,46 & 1,97 & 100,74 & 2,20 & 99,79 & 2,66 \\
\hline-5 & 100 & 0,63 & 101,73 & 1,88 & 100,97 & 1,96 & 100,34 & 2,19 & 99,59 & 2,66 \\
\hline$-10+\mathrm{A}$ & 100 & 0,64 & 101,52 & 1,88 & 100,70 & 1,96 & 100,07 & 2,19 & 99,29 & 2,65 \\
\hline$-20+\mathrm{A}$ & 100 & 0,62 & 101,44 & 1,87 & 100,65 & 1,95 & 99,93 & 2,18 & 98,86 & 2,64 \\
\hline$-30+\mathrm{A}$ & 100 & 0,64 & 101,33 & 1,87 & 100,57 & 1,96 & 99,85 & 2,18 & 98,75 & 2,64 \\
\hline
\end{tabular}

Table 3 The transfer standard calibration factor $K_{I}$ and $\left|\Gamma_{E G}\right|$ from certificates of calibration determined in calibration laboratory TEGAM and values of the reflection coefficients modules $\left|\Gamma_{U}\right|$ of DUT sensor E4413A measured in TTC with VNA and measurement uncertainties $U(k=2)$

\begin{tabular}{|c|c|c|c|c|c|c|}
\hline & \multicolumn{4}{|c|}{ Transfer standard calibrated in TEGAM, $(k=2)$} & \multicolumn{2}{|c|}{ DUT sensor calibrated in TTC } \\
\hline$f / \mathrm{GHz}$ & $K_{I}$ & $U\left(K_{I}\right) / \%$ & \begin{tabular}{|l|l|} 
& $\Gamma_{E G}$
\end{tabular} & \begin{tabular}{c|c|c}
$U($ & $\Gamma_{E G}$ & )$_{\max }$ \\
\end{tabular} & \begin{tabular}{|l|l|}
$\Gamma_{U}$ & $E 4413 \mathrm{~A}$ \\
\end{tabular} & $U\left(\left|\Gamma_{U}\right|\right)_{\max }$ \\
\hline 0,05 & 0,9900 & 1,19 & 0,0025 & 0,028 & 0,026 & 0,010 \\
\hline 2 & 0,9438 & 1,18 & 0,0095 & 0,028 & 0,020 & 0,010 \\
\hline 6 & 0,9149 & 1,27 & 0,0181 & 0,028 & 0,013 & 0,010 \\
\hline 12 & 0,8441 & 1,44 & 0,0377 & 0,028 & 0,008 & 0,010 \\
\hline 18 & 0,8009 & 1,84 & 0,0294 & 0,028 & 0,007 & 0,010 \\
\hline
\end{tabular}

$\delta_{I}$ is temperature drift of the transfer standard declared for $\pm 0,05 \%$ at temperature of $(23 \pm 1)^{\circ} \mathrm{C}$, the rectangular distribution is assumed, uncertainty is type B.

$p_{k}$ is the connector repeatability uncertainty, for connector SMA $3,5 \mathrm{~mm}$ at $18 \mathrm{GHz}$ it is $\max . \pm 0,2 \%$, the normal distribution is assumed, uncertainty is type A.

$M_{U f}, M_{U r e f}$ is the mismatch factor between the transfer standard and the DUT at frequency $f$ and the reference frequency of $50 \mathrm{MHz}$. Value of the mismatch factor $M_{U}$ is defined by Eq. (1). In accordance with [2, 7] standard mismatch uncertainty $u\left(M_{U}\right)$ is determined by Eq. $u\left(M_{U}\right)=\sqrt{2}\left|\Gamma_{E G}\right|\left|\Gamma_{U}\right|$. Values of the $\Gamma_{E G}$ and $\Gamma_{U}$ modules are shown in Tab. 3. The U-shaped distribution is assumed, uncertainty is type $\mathrm{B}$.

$A_{f}, A_{\text {ref }}$ is attenuation of the attenuator $\mathrm{A}$ at frequency $f$ and at the reference frequency of $50 \mathrm{MHz}$. Attenuations 
within the $50 \mathrm{MHz}$ to $18 \mathrm{GHz}$ frequency range were determined with the expanded measurement uncertainty $U$ $(k=2)$ from $0,03 \%$ to $0,09 \%$. For the case of calibration when the additional attenuator is not used then the value is $A_{f}=A_{\text {ref }}=1$ and is not taken into account in calculations in Eq. (11). The normal distribution is assumed, uncertainty is type $\mathrm{B}$.

$\sigma_{n}$ is measurement repeatability of the calibration factor $K_{\text {DUT }}$. Standard deviation $\sigma$ of a single measurement is $<0,1 \%$, and standard uncertainty of the mean value $\sigma_{n}$ (for 4 repeated measurements, $n_{p} \geq 4, \sigma_{n}=\sigma / \sqrt{n_{p}}$ ) is $\pm 0,05 \%$, The normal distribution, uncertainty is type A.

In calculating the calibration factor $K_{\mathrm{DUT}}$, according to Eq. (11), it was assumed that contributing quantities $\delta_{C F}$, $n_{l}, \delta_{I}, p_{k}, M_{U f}, M_{U r e f}$ have the value 1 , and $\sigma_{n}=0$. Their real values are taken into account only in the measurement uncertainty budget using their standard measurement uncertainty. It is estimated that none of the contributing quantities is correlated with other contributing quantities. The analysis of measurement uncertainty in power sensor calibration was carried out in compliance with recommendations given in EA-4/02M [22]. Tab. 1 displays characteristic examples of the measurement uncertainty budget for diode sensor calibration at the frequency of $12 \mathrm{GHz}$, without the attenuator for the power level of $13 \mathrm{dBm}$ and with the attenuator A for the power level of $-30 \mathrm{dBm}$. Tab. 2 gives a summary of the measured values for the calibration factor $K_{\text {DUT }}$ and the calculation results for expanded measurement uncertainty $U$ of the diode sensor calibration for the characteristic power levels and frequencies. In the tables and the text before, $X_{i}$ is the quantity name, $x_{i}$ is the quantity value estimation, $u\left(x_{i}\right)$ is the standard uncertainty, Dist/Type refers to the probability distribution and uncertainty type $\mathrm{A} / \mathrm{B}, c_{i}$ are the sensitivity coefficients obtained using partial derivatives of all contributing quantities in Eq. (11) and $u_{i}(y)$ is the uncertainty contribution [22]. The combined measurement uncertainty $u_{c}$ was obtained based on Eq. (12), and expanded uncertainty of measurement $U$ was obtained for the coverage factor $k=2$.

$$
u_{c}^{2}\left(y_{\mathrm{DUT}}\right)=\sum_{i=1}^{m} c_{i}^{2} u^{2}\left(x_{i}\right)=\sum_{i=1}^{m} u_{i}^{2}(y)
$$

\section{EXPERIMENTAL RESULTS}

Fig. 4 shows graphic representation of the calibration factor $\left(K_{\text {DUT }}\right)$ for the E4413A diode sensor, calibrated by applying a new method at different calibration power levels $(13,10,7,5,0,-5,-10,-20,-30) \mathrm{dBm}$, in the frequency range of $50 \mathrm{MHz}$ to $18 \mathrm{GHz}$. Labels (TE) on graphs denote that $K_{\text {DUT }}$ for the respective power level was measured using the transfer standard, whereas labels $(\mathrm{TE}+\mathrm{A})$ denote that $K_{\text {DUT }}$ for the respective power level was measured with the transfer standard and additional attenuator $20 \mathrm{~dB}$ for $(-10,-20,-30) \mathrm{dBm}$. Due to limited measuring capacities of the calibration system, all measurements were carried out in the frequency range of $50 \mathrm{MHz}$ to $18 \mathrm{GHz}$ for the power levels from $-30 \mathrm{dBm}$ to $13 \mathrm{dBm}$. The calibration factors' numerical values and expanded measurement uncertainty $U$ for characteristic frequencies and calibration power levels of the E4413A diode sensor are shown in Tab. 2.

Fig. 5 is a graphic representation of the calibration factor $\left(K_{\mathrm{DUT}}\right)$ for the $8485 \mathrm{~A}$ thermocouple sensor, calibrated by the new method for the calibration power levels $(10,0,-10,-20) \mathrm{dBm}$, in the frequency range of $50 \mathrm{MHz}$ to $18 \mathrm{GHz}$. Declared measuring range of the $8485 \mathrm{~A}$ sensor is from $20 \mathrm{dBm}$ to $-30 \mathrm{dBm}$, so that measurements at the end of the measuring range, for the power levels below $-20 \mathrm{dBm}$, were not considered in the analysis. Fig. 6 shows nonlinearity of the E4413A diode sensor for the power levels $(13,10,7,5,-5,-10,-20,-30) \mathrm{dBm}$ in the $50 \mathrm{MHz}$ to $18 \mathrm{GHz}$ frequency range. Fig. 7 presents nonlinearity of the HP 8485A thermocouple sensor, for the power levels $(10,-10,-20) \mathrm{dBm}$ in the frequency range of $50 \mathrm{MHz}$ to $18 \mathrm{GHz}$. Sensor nonlinearities in Fig. 6 and Fig. 7 were obtained by applying the new calibration method and derived new formula for sensor nonlinearity, Eq. (4) for $P_{\text {ref }}=0 \mathrm{dBm}$.

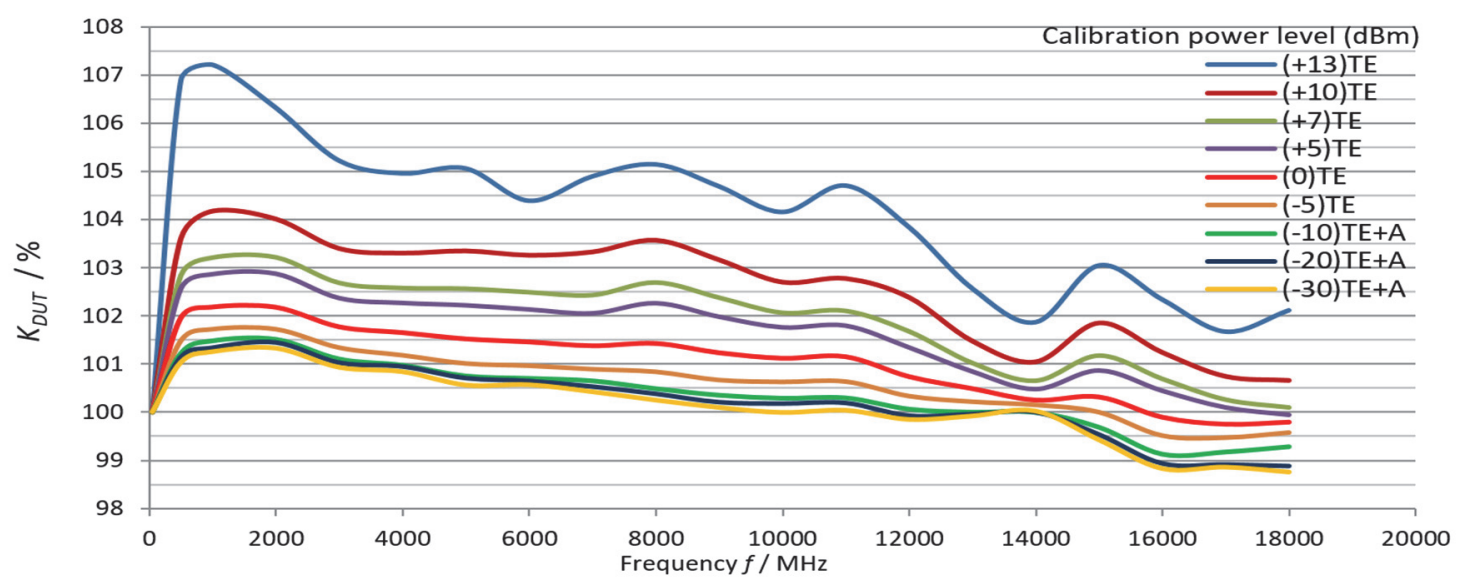

Figure 4 Calibration factors $\left(K_{D U T}\right)$ for the E4413A diode sensor measured by the improved method for different calibration power levels

\section{VALIDATION AND DISCUSSION}

The validation of the improved method and the automated measuring system was realized in two phases, expanding the results of our previous short report [20]. In phase one, the results of comparing manufacturer calibration factor values of Agilent E4413A diode sensor and values obtained in the TTC laboratory are used for 
validation of basic method and automated measurement system itself. Several successive measurements of calibration factor were performed (on reference power level $P_{r e f}=0 \mathrm{dBm}$ ) and several measurements were carried out in two-day intervals in the TTC [20].

Values of E4413A sensor calibration factor determined by manufacturer calibration laboratory, go from $99,7 \%$ to $101,9 \%$ along with expanded uncertainty $(k=2)$ between $1,6 \%$ and $2,5 \%$ in the frequency range of $50 \mathrm{MHz}$ to $18 \mathrm{GHz}$. Results of measurements are shown in Tab. 4 [20]. Column 2 represents the Agilent calibration factor values, column 3 is measurement uncertainty of E4413A sensor calibration factor $(k=2)$ defined by Agilent calibration laboratory, columns 4 and 6 represent calibration factor values successively measured in the TTC. Column 5 shows the difference between calibration factor values determined by Agilent (column 2) and calibration factor values measured in TTC (columns 4), while column 7 shows calibration factor measurement repeatability in TTC (columns 4 - 6).

Repeatability of calibration factor measurement results obtained by usage of automated measurement system, for two successive measurements, without DUT reconnection (column 7), is max. 0,1\%. Repeatability of calibration factor measurements after two days, with DUT reconnections, is max. $0,4 \%$ [20].

Comparation of calibration factor values provided by manufacturer and values measured in TTC (column 5) shows that difference is within the range from 0 to $0,9 \%$ depending on frequency.

\begin{tabular}{|c|c|c|c|c|c|c|}
\hline 1 & 2 & 3 & 4 & 5 & 6 & 7 \\
\hline$\underset{/ \mathrm{GHz}}{f}$ & $\begin{array}{c}\text { Agilent } C F \\
/ \%\end{array}$ & $\begin{array}{c}\text { Agilent } \\
U(C F) \\
/ \%\end{array}$ & $\begin{array}{c}T T C_{1} \\
C F \\
/ \%\end{array}$ & $\begin{array}{c}\Delta C F / \\
\% \\
(2-4)\end{array}$ & $\begin{array}{c}T T C_{2} \\
C F \\
/ \%\end{array}$ & $\begin{array}{c}\operatorname{Re} \\
/ \% \\
(4-6) \\
\end{array}$ \\
\hline 0.05 & 100 & 1,6 & 100 & 0 & 100 & 0 \\
\hline 0.5 & 101,9 & 2,1 & 101,9 & 0 & 102,0 & $-0,1$ \\
\hline 1 & 101,9 & 2,1 & 102,2 & $-0,3$ & 102,3 & $-0,1$ \\
\hline 2 & 101,9 & 2,2 & 102,5 & $-0,6$ & 102,6 & $-0,1$ \\
\hline 3 & 101,5 & 2,2 & 102,2 & $-0,7$ & 102,3 & $-0,1$ \\
\hline 4 & 101,4 & 2,2 & 102,1 & $-0,7$ & 102,2 & $-0,1$ \\
\hline 5 & 101,3 & 2,2 & 102,1 & $-0,8$ & 102,1 & 0 \\
\hline 6 & 101,2 & 2,2 & 102,0 & $-0,8$ & 102,0 & 0 \\
\hline 7 & 101 & 2,2 & 101,9 & $-0,9$ & 101,9 & 0 \\
\hline 8 & 101,2 & 2,3 & 101,9 & $-0,7$ & 102,0 & $-0,1$ \\
\hline 9 & 101,1 & 2,3 & 101,7 & $-0,6$ & 101,7 & 0 \\
\hline 10 & 100,8 & 2,3 & 101,6 & $-0,8$ & 101,6 & 0 \\
\hline 11 & 100,8 & 2,3 & 101,6 & $-0,8$ & 101,5 & 0,1 \\
\hline 12 & 100,6 & 2,3 & 101,1 & $-0,5$ & 101,2 & $-0,1$ \\
\hline 13 & 100,4 & 2,3 & 101,0 & $-0,6$ & 101,0 & 0 \\
\hline 14 & 99,7 & 2,4 & 100,5 & $-0,8$ & 100,5 & 0 \\
\hline 15 & 100,4 & 2,4 & 101,0 & $-0,6$ & 101,0 & 0 \\
\hline 16 & 99,8 & 2,4 & 100,2 & $-0,4$ & 100,2 & 0 \\
\hline 17 & 99,9 & 2,4 & 100,8 & $-0,9$ & 100,8 & 0 \\
\hline 18 & 100,1 & 2,5 & 100,8 & $-0,7$ & 100,8 & 0 \\
\hline
\end{tabular}

Connector repeatability, mismatch uncertainty, sensor temperature drift, cable deflection and measurement repeatability have to be considered during interpretation of these results.

Analysis of measurement results (Tab. 4) shows that system is stable and that has good measurement repeatability $(\leq 0,1 \%)$. Difference between values of calibration factor provided by manufacturer calibration laboratory and values measured in TTC is less than $1 \%$. Expanded measurement uncertainty of E4413A sensor calibration factor $(k=2)$, defined by Agilent lies within $1,6 \%$ and $2,5 \%$, while expanded measurement uncertainty determined in TTC lies within $0,62 \%$ and 2,66\%, (Tab. 2). According to these results difference in calibration factor, which is less than $1 \%$, is acceptable and it is within limits of measurement uncertainty.

Regarding the measurement results and analysis, validation of the basic method might be considered as successful and automated measurement system can be effectively applied for calibration factor determination with acceptable measurement uncertainty.

In phase two, the validation of improved method and measurement results shown in graphs 4 - 7 was conducted based on the analysis of data obtained by measurements and comparison with nonlinearity specified by manufacturer for the two types of sensors. The Agilent E4413A diode sensor declared linearity is $\pm 3 \%$ from $-70 \mathrm{dBm}$ to $10 \mathrm{dBm}$ and $\pm 4,5 \%$ from $10 \mathrm{dBm}$ to $20 \mathrm{dBm}$, for $t=(25 \pm 5)^{\circ} \mathrm{C}$ and from $\pm 7 \%$ to $\pm 10 \%$ for $t=(0-55)^{\circ} \mathrm{C}$. The HP $8485 \mathrm{~A}$ thermocouple sensor linearity is $\pm 3 \%$, in the $10 \mathrm{dBm}$ to $20 \mathrm{dBm}$ range, and is negligibly small outside of that power range [12]. The "unknown attenuator" method, for extending the measurement range, was validated in document $[18,23]$ and is not discussed in this paper.

It is noticeable for the diode sensor (Fig. 4) that the difference between calibration factors $K_{\text {DUT }}(13 \mathrm{dBm})$ and $K_{\text {DUT }}(-30 \mathrm{dBm})$ ranges from $6 \%$ for the frequency of $1 \mathrm{GHz}$ to $1,8 \%$ for $14 \mathrm{GHz}$. If a single power level of $-30 \mathrm{dBm}$ is observed, the value of $K_{\text {DUT }}(-30 \mathrm{dBm})$ ranges from $101,33 \%$ to $99,42 \%\left(K_{\max }-K_{\min }=1,91 \%\right)$, whereas for the power level of $13 \mathrm{dBm} K_{\text {DUT }}(13 \mathrm{dBm}), K_{\max }-K_{\min }$ value is $5,55 \%$, in the $50 \mathrm{MHz}$ to $18 \mathrm{GHz}$ frequency range. Obviously, the calibration factor $\left(K_{\mathrm{DUT}}\right)$ of the diode sensor has a significant dependence on the calibration power level as well as on frequency.

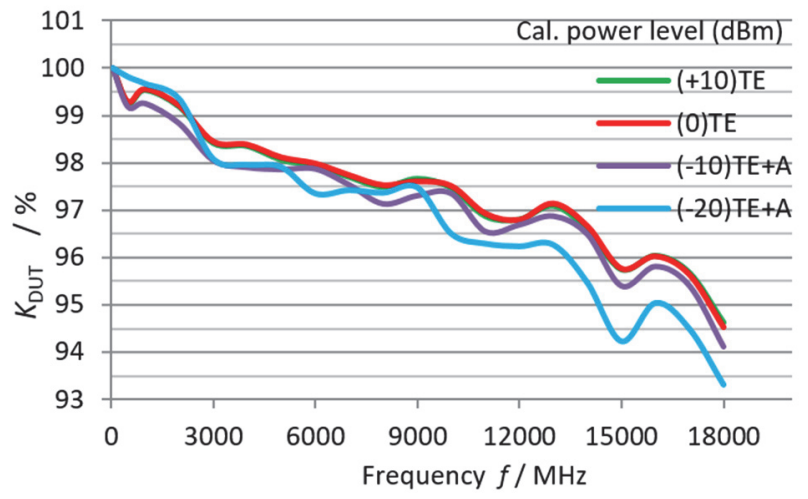

Figure 5 Calibration factors (KDUT) for the 8485A thermocouple sensor measured for different calibration power levels

In Fig. 5, drawn for the thermocouple sensor, it is noticeable that for the power level of $10 \mathrm{dBm}$ the calibration factor value ( $K_{\text {DUT }}$ ) ranges from $100 \%$ to $94,63 \%$ in the observed frequency range. If a single frequency is observed $(18 \mathrm{GHz})$, maximal differences of the $K_{\text {DUT }}$ for the power levels of $0 \mathrm{dBm}, 10 \mathrm{dBm}$ and $-10 \mathrm{dBm}$ are very small and amount to less than $0,52 \%$, while maximal differences at power level of $-20 \mathrm{dBm}$ are less than $1,32 \%$. 
Observing graphs in Fig. 4 and Fig. 5 leads to the conclusion that established differences in the values of $K_{\text {DUT }}$ are the result of sensor nonlinearity and different power levels of sensor calibration. The new method and measuring system calibrate sensors successfully at several different power levels, detecting sensor nonlinearity at the same time. Graphs in Fig. 4 and Fig. 5 show simultaneously the dependence of calibration factors on frequency as well as on different calibration power levels, which has been rarely encountered in the literature so far.

Graphs in Fig. 6 and Fig. 7 report calculated values of sensor nonlinearity and confirm the dependence on change in the power level and on frequency. From graph in Fig. 6 it is evident for diode sensor that nonlinearity, in the observed frequency range and power range, is from $4,92 \%$ to $-0,92 \%$ for $1 \mathrm{GHz}$ and from $1,62 \%$ to $-0,23 \%$ for
$14 \mathrm{GHz}$, whereas Fig. 7 shows that nonlinearity for the thermocouple sensor ranges from $0,53 \%$ to $-1,59 \%$. Graph 6 indicates that diode sensor nonlinearity for the power levels from $10 \mathrm{dBm}$ to $-30 \mathrm{dBm}$ is within the $2,11 \%$ to $-1,16 \%$ limits (declared $< \pm 3 \%$ ), and for the $10 \mathrm{dBm}$ to $13 \mathrm{dBm}$ power levels within the limits of $1,5 \%$ to $3,5 \%$ (declared $< \pm 4,5 \%$ ), for the majority of measuring points (and to max. 4,92\%). It is seen from Fig. 7 that thermocouple sensor nonlinearity for the $-10 \mathrm{dBm}$ to $10 \mathrm{dBm}$ power levels is very small, amounting to $\leq \pm 0,5 \%$, and for the power levels to $-20 \mathrm{dBm}$ is from $0,5 \%$ to $-1 \%$ (max. 1,6\%). Measured nonlinearity values (Fig. 6 and Fig. $7)$, practically confirm the manufacturer's declared nonlinearity of diode and thermocouple sensors.

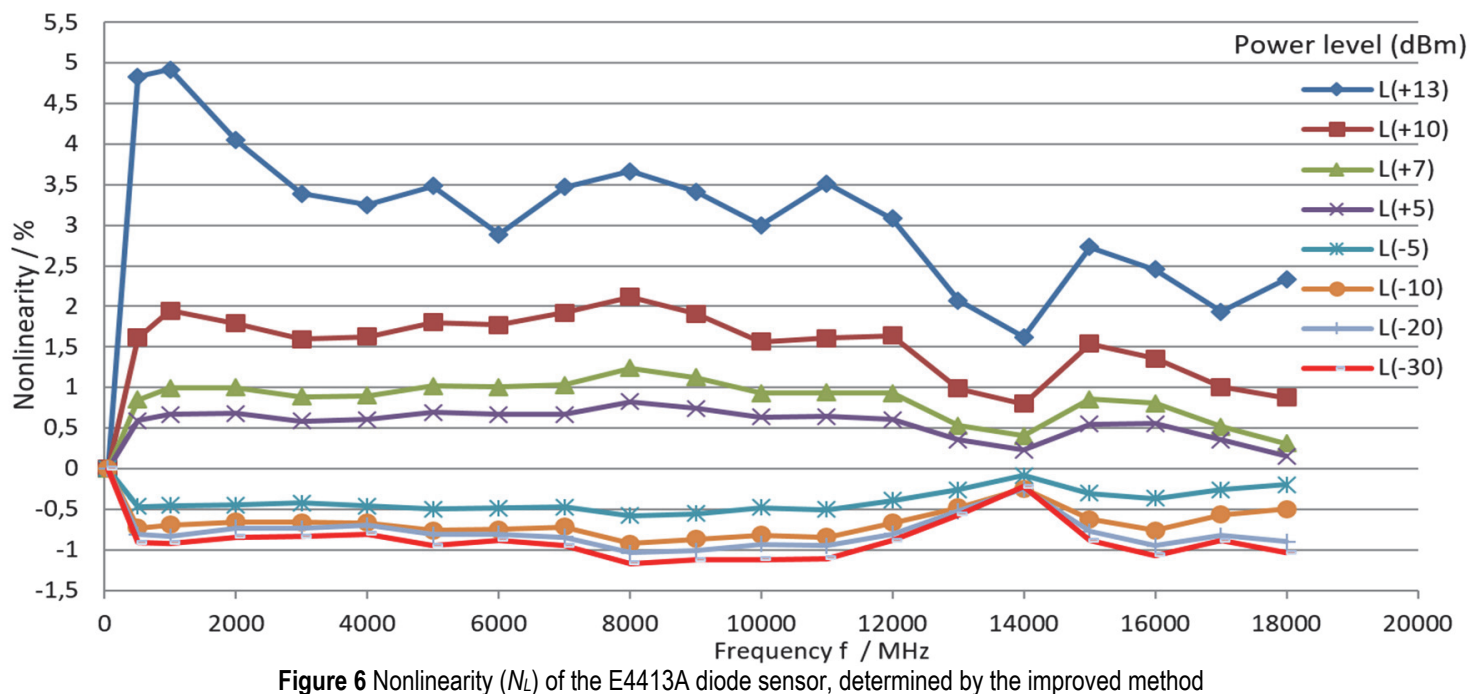

Based on graphs in Fig. 4 to Fig. 7, measurement results and comparison with characteristics declared by the manufacturer [12], the applicability of the described improved method and measuring system can be confirmed for power sensor nonlinearity calibration in the range between $-30 \mathrm{dBm}$ and $13 \mathrm{dBm}$. The analysis of obtained results (Fig. 6 and Fig. 7) leads to conclusion that sensor linearity is dominantly power-level dependent, but also signal-frequency dependent, which must not be disregarded, especially in the most precise measurements. Based on presented research results, we conclude that the sensor nonlinearity cannot be measured only at one frequency in the most precise measurements, as has been practiced so far $[5,13,17]$.

It is noticeable from Fig. 6 that maximum and minimum absolute values of diode sensor nonlinearity amount from $4,92 \%$ (for $1 \mathrm{GHz}$ ) to $0,09 \%$ (for $14 \mathrm{GHz}$ ). These nonlinearity values are matched by the error due to nonlinearity of the significance $\pm 0,2 \mathrm{~dB}$ (for $4,92 \%$ ) to negligible $\pm 0,004 \mathrm{~dB}$ (for $0,09 \%$ ) in power measurement. Sensor nonlinearity is commonly within the $1 \%$ to $5 \%$ limits [12], which significantly contributes to the increase of power measurement uncertainty. The application of improved calibration method and calibration factors defined at several power levels allows for power sensor nonlinearity correction and eliminates measurement uncertainty due to sensor nonlinearity. The application of such nonlinearity correction is of particular significance in calibration and test laboratories for the most precise measurements of absolute microwave power and attenuation value.

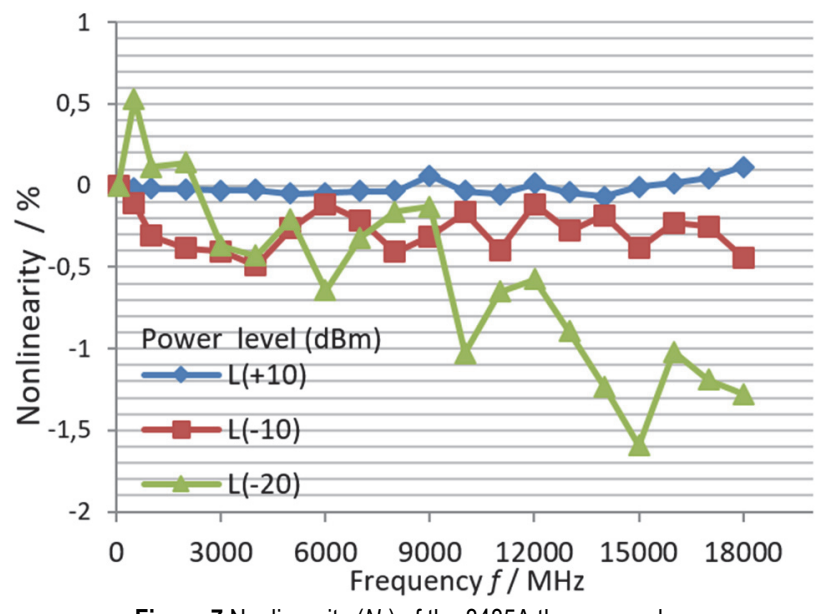

Figure 7 Nonlinearity $\left(N_{L}\right)$ of the $8485 \mathrm{~A}$ thermocouple sensor

In order to evaluate the proposed method, an example of the measurement uncertainty budget of the output power of a signal generator (for the power level of $13 \mathrm{dBm}$ at the frequency of $6 \mathrm{GHz}$ ), using the E4419B power meter and E4413A diode sensor, without and with sensor nonlinearity correction is shown in Tab. 5. Values given in Tab. 5 
denoted with "*" refer to corrected values after the application of the improved calibration method and performed sensor nonlinearity correction. Value of the expanded measurement uncertainty of the calibration factor $K_{\text {DUT }}$ determination for the E4413A sensor, for the power level of $0 \mathrm{dBm}$ and frequency of $6 \mathrm{GHz}$ (classical method) is $1,97 \%$, and for the power level of $13 \mathrm{dBm}$ and frequency of $6 \mathrm{GHz}$ (determined by the improved method) is $2,03 \%$ (Tab. 2). The sensor nonlinearity value for the power level of $13 \mathrm{dBm}$ is declared for $4,5 \%$ and this value is included in the power measurement uncertainty budget and is completely eliminated after the nonlinearity correction [12]. It can be seen from the analysis in Tab. 5 that expanded power measurement uncertainty for the level of $13 \mathrm{dBm}$ and frequency of $6 \mathrm{GHz}$, amounted to $5,77 \%$ without correction, and $3,64 \%$ with nonlinearity correction. Absolute value of power measurement uncertainty reduction is $2,13 \%$, and relative power measurement uncertainty reduction is by $36,9 \%$.

Table 5 Power measurement uncertainty budget of the diode E4413A sensor for $13 \mathrm{dBm}$, at $6 \mathrm{GHz}$, using classical or improved method (*) for sensor calibration, (without correction nonlinearity and with applied nonlinearity correction *)

\begin{tabular}{|c|c|c|c|c|c|c|c|}
\hline Source of Uncertainty & Symbol & $\begin{array}{l}\text { Value } \\
\text { without correction } \\
\qquad / \pm\end{array}$ & $\begin{array}{l}\text { Probability } \\
\text { Distribution }\end{array}$ & Divisor & $\begin{array}{c}\text { Standard } \\
\text { Uncertainty } \\
\text { without } \\
\text { correction } \\
/ \%\end{array}$ & $\begin{array}{c}* \text { Value } \\
\text { with correction } \\
/ \pm\end{array}$ & $\begin{array}{c}* \text { Standard } \\
\text { Uncertainty } \\
\text { with } \\
\text { correction } \\
/ \% \\
\end{array}$ \\
\hline $\begin{array}{l}\text { Sensor calibration factor } \\
\text { Expanded uncertainty }\end{array}$ & $K_{\text {DUT }}$ & $1,97 \%$ & Gaussian & 2 & 0,985 & $2,03 \%$ & $1,015 *$ \\
\hline Power sensor nonlinearity & $N_{L}$ & $4,50 \%$ & Gaussian & 2 & 2,25 & $0,00 \%$ & $0,000 *$ \\
\hline $\begin{array}{l}\text { Mismatch gain between } \\
\text { generator and sensor }\end{array}$ & $M u$ & 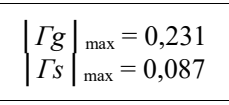 & $\begin{array}{c}|\Gamma g|,|\Gamma s| \\
\text { uniform inside } \\
\text { circle }\end{array}$ & $\sqrt{2}$ & 1,421 & 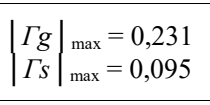 & 1,421 \\
\hline $\begin{array}{c}\text { Mismatch gain between } \\
\text { calibration source and sensor } \\
\text { at } 50 \mathrm{MHz}\end{array}$ & Muc & $\begin{array}{l}|\Gamma c s|_{\max }=0,029 \\
|\Gamma s|_{\max }=0,095\end{array}$ & $\begin{array}{c}|\Gamma c s|,|\Gamma s| \\
\text { uniform inside } \\
\text { circle }\end{array}$ & $\sqrt{2}$ & 0,195 & $\begin{array}{l}|\Gamma c s|_{\max }=0,029 \\
|\Gamma s|_{\text {max }}=0,095\end{array}$ & 0,195 \\
\hline $\begin{array}{c}\text { Power meter instrumentation } \\
\text { Error }\end{array}$ & $P m$ & $0,5 \%$ & Rectangular & $\sqrt{3}$ & 0,289 & $0,5 \%$ & 0,289 \\
\hline $\begin{array}{l}\text { Power meter instrumentation } \\
\text { Error during calibration }\end{array}$ & $P m c$ & $0,5 \%$ & Rectangular & $\sqrt{3}$ & 0,289 & $0,5 \%$ & 0,289 \\
\hline Calibrator output power Error & Pcal & $0,50 \%$ & Gaussian & 2 & 0,25 & $0,50 \%$ & 0,25 \\
\hline Power meter drift & $D$ & $\pm 15 \mathrm{pW}$ & Rectangular & $\sqrt{3}$ & 0 & $\pm 15 \mathrm{pW}$ & 0 \\
\hline Power meter zero set & $Z s$ & $\pm 50 \mathrm{pW}$ & Rectangular & $\sqrt{3}$ & 0 & $\pm 50 \mathrm{pW}$ & 0 \\
\hline Power meter and sensor noise & $N$ & $\pm 70 \mathrm{pW}$ & Rectangular & $\sqrt{3}$ & 0 & $\pm 70 \mathrm{pW}$ & 0 \\
\hline Combined uncertainty RSS & & & & & 2,884 & & 1,821 \\
\hline Expanded measur. uncertainty & $U$ & \multicolumn{2}{|c|}{ Coverage factor $k=2$} & & $5,77 \%$ & & $* 3,64 \%$ \\
\hline
\end{tabular}

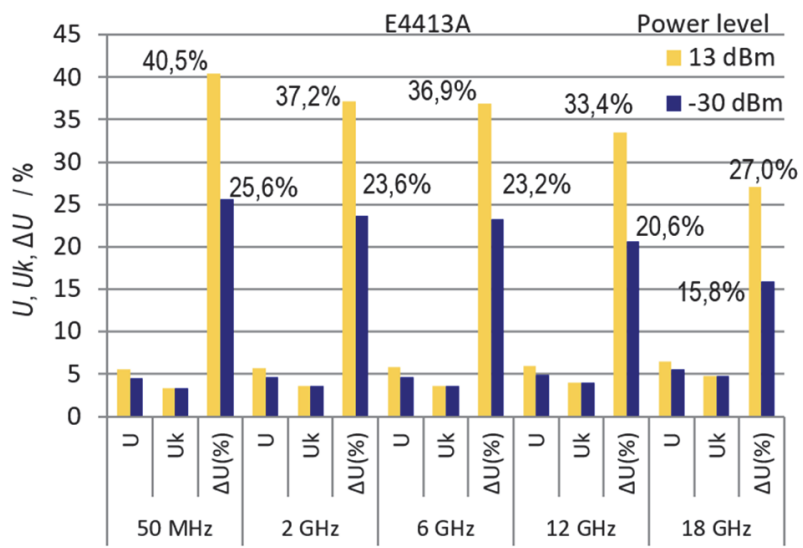

Figure 8 Relative reduction of power measurement uncertainty after nonlinearity correction $(\Delta U)$, for power levels $13 \mathrm{dBm}$ and $-30 \mathrm{dBm}$

Graph in Fig. 8 reports calculated values of expanded power measurement uncertainty using a E4413A sensor without correction application and using a sensor with nonlinearity correction for the power levels of $13 \mathrm{dBm}$ and $-30 \mathrm{dBm}$ and for frequencies $50 \mathrm{MHz},(2,6,12,18) \mathrm{GHz}$. In Fig. 8 the expanded power measurement uncertainty using a sensor without nonlinearity correction is denoted by $(U)$, the expanded power measurement uncertainty using a sensor with nonlinearity correction is denoted by $\left(U_{k}\right)$, and relative measurement uncertainty reduction after nonlinearity correction is denoted by $\Delta U$, i.e. $\Delta U(\%)=\left(U-U_{k}\right) / U \times 100 \%$.

It is visible from the analysis in Fig. 8 that nonlinearity correction reduces power measurement uncertainty for the $13 \mathrm{dBm}$ level from $27,0 \%$ (for $18 \mathrm{GHz}$ ) to $40,5 \%$ (for $50 \mathrm{MHz}$ ), and for the $-30 \mathrm{dBm}$ power level measurement uncertainty is reduced from $15,8 \%$ (for $18 \mathrm{GHz}$ ) to $25,6 \%$ (for $50 \mathrm{MHz}$ ).

This can be considered as a significant reduction of the power measurement uncertainty and improving the measurement characteristics of power sensors up to $40 \%$.

\section{CONCLUSION}

An improved method and automated measuring system for power sensor calibration and simultaneous measurement of the power sensor nonlinearity are presented in the paper.The experimental results confirmed dominant dependence of sensor nonlinearity on the power level, but also proved significant dependence of sensor nonlinearity on the signal frequency. The power measurement uncertainty budget shows that through the process of sensor calibration, measurement and correction of sensor nonlinearity on different power levels and frequencies (i.e. by applying the novel method) a significant reduction in power measurement uncertainty 
can be obtained, in the range of $15,8 \%$ to even $40,5 \%$ (for diode sensor). The novel method enables the maximum possible correction of the sensor nonlinearity, and also improves the measurement characteristics of the existing power sensors. Testing and validation, conducted by a series of experimental measurements, confirmed the high performance of the novel method and proved its applicability for calibrating nonlinearity of power sensor in the dynamic range between $-43 \mathrm{dBm}$ and $13 \mathrm{dBm}$, with acceptable measurement uncertainty.

The novel method can be applied in metrological laboratories, in order to calibrate the power sensors, which can be used for calibration of signal generators, attenuators, directional couplers and other demanding microwave power measurements.

\section{REFERENCES}

[1] Fantom, A. (1990). Radio frequency and microwave power measurement. London, UK: Peter Peregrinus. https://doi.org/10.1049/PBEL007E

[2] Agilent Technologies. (2001). Agilent fundamentals of $R F$ and microwave power measurements:Application Note 64-1C (Publication No. 5965-6630E).

[3] Holland, K. \& Howes, J. (2002). Improvements to the microwave mixer and power sensor linearity measurement capability at the NPL.IEE Proceedings-Science Measurement and Technology, 149(6), 329-332. https://doi.org/10.1049/ip-smt:20020639

[4] Brunetti, L. (2001). Accuracy assessment in HF power meter calibration. Proceedings of the11th IMECO TC-4 Symposium: Trends in Electrical Measurements and Instrumentation, 233-237. Retrieved from https://www.imeko.org/publications/tc4-2001/IMEKOTC4-2001-069.pdf

[5] Brunetti, L., Oberto, L., \& Vremera, E. (2006). Calibration concept of modern power meters.Proceedings of XVIII IMEKO World Congress: Metrology for a Sustainable Development. Retrieved from https://citeseerx.ist.psu.edu/ viewdoc/download?doi=10.1.1.506.8371\&rep=rep1\&type= pdf

[6] Brunetti, L. \& Monticone, E. (1988). Resistive power splitter in microwave power standard calibration transfer. Measurement, 6(3), 129-134. https://doi.org/10.1016/S0263-2241(88)80006-X

[7] Brunetti, L., Shan, Y., Oberto, L., Chua, C.W., Sellone, M., \& Terzi, P. (2012). High frequency comparison with thermoelectric power sensors between INRIM and NMC. Measurement, 45(5), 1180-1187. https://doi.org/10.1016/j.measurement.2012.01.019

[8] Weidman, P. M. (1996). NIST Technical note 1379: Direct comparison transfer of microwave power sensor calibrations. Washington, USA: NIST. https://doi.org/10.6028/NIST.TN.1379

[9] Shan, Y., Meng, S. Y., \& Lin, Z. (2013). Generic model and case studies of microwave power sensor calibration using direct comparison transfer.IEEE Transactions on Instrumentation and Measurement, 62(6), 1834-1839. https://doi.org/10.1109/TIM.2012.2225961

[10] Shan, Y. \& Cui, X. (2012).RF and microwave power sensor calibration by direct comparison transfer. L. Cocco (Ed.). Modern metrology concerns, 175-200. https://doi.org/10.5772/34553

[11] TEGAM. (2015). Coaxial RF power standard instruction and service manual model F1135A(Publication No. PNHIM300 Rev. R).
[12] Agilent Technologies. (2009). Agilent E4418B/E4419B EPM series power meters, E-series and 8480 series power sensors data sheet (Publication No.5965-6382E).

[13] Schwarz, M. (2013). Testing linearity on the Agilent E441xA power sensors. Cal Lab: The International Journal of Metrology, 20(3), 23-26. Retrieved fromhttps://www.callabmag.com/wpcontent/uploads/2013/09/jul13.pdf

[14] TEGAM (2015). Measuring RF power sensor nonlinearity (Publication No. AN220). Retrieved from https://www.tegam.com/wp-content/uploads/2015/10/ AN220.pdf

[15] Cletus, A. H., Keith, C. R., \& Mckay, A. (1976). Measuring and minimizing diode detector nonlinearity. IEEE Transactions on Instrumentation and Measurement, IM25(4), 324-329. https://doi.org/10.1109/TIM.1976.6312236

[16] Cherry, P., Oram, W., \& Hjipieris, G. (1995, May). Adynamic calibrator for detector non-linearity characterization. Microwave Engineering Europe, 43-46.

[17] Costner, A. (1998).Aspects of calibration power splitters and detector linearity. Proceedings of the 27th ARMMS Conference. Retrieved from http://www.armms.org/ conferences $/$ ? conference $=20$

[18] Yhland, K., Stenarson, J., \& Wingqvist, C. (2010). Power sensor linearity calibration with an unknown attenuator.Proceedings of the 27 th Conference on Precision Electromagnetic Measurements (CPEM 2010), 769-770. https://doi.org/10.1109/CPEM.2010.5544323

[19] Coster, A. (2007). Attenuation measurements.In R. J. Collier, \& A. D. Skinner (Eds.),Microwave measurements 3rd edition, 91-120. London, UK: IET. https://doi.org/10.1049/PBEL012E_ch5

[20] Rakonjac, P., Milovanović, B., \& Dončov, N. (2008). Automated power sensors calibration up to $26.5 \mathrm{GHz}$. Microwave Review, 14(2), 20-27. Retrieved from http://www.mtt-serbia.org.rs/files/MWR-issues/134

[21] Crowley, T. P., Miall, J., de Vreede, J. P. M., Furrer, J., Michaud, A., Dressler, E., Zhang,T., Shimaoka, K., \& Kim, J. H. (2006).CCEM.RF-S1.CL (GTRF/02-03): RF power measurements with $2.4 \mathrm{~mm}$ connectors.Metrologia, 43(1A), 01007. https://doi.org/10.1088/0026-1394/43/1A/01007

[22] EA Laboratory Committee. (2013). Evaluation of the Uncertainty of Measurement in Calibration (Publication No. EA-4/02M:2013). Retrieved fromhttps://europeanaccreditation.org/wp-content/uploads/2018/10/ea-4-02-mrev01-september-2013.pdf

[23] Furrer, J. \& Yhland, K. (2010). EURAMET project 1129: Characterization of $R F$ diode power sensors. EURAMET. Retrieved from https://www.euramet.org/index.php?eID= tx_securedownloads $\& \mathrm{p}=529 \& \mathrm{u}=0 \& \mathrm{~g}=0 \& \mathrm{t}=1649772282 \&$ hash $=15 \mathrm{a} 8 \mathrm{cea} 75 \mathrm{ae} 8 \mathrm{f} 7 \mathrm{af} 9044 \mathrm{f} 396 \mathrm{ccda} 8089620 \mathrm{~d} 36 \mathrm{~d} 8 \&$ file $=$ Media/docs/projects/EURAMETP1129_ELECT_Final_Rep ort.pdf 


\section{Contact information:}

Predrag RAKONJAC, mag. ing. el.

(Corresponding author)

Technical Test Center (TTC),

Vojvode Stepe 445A, 11000 Belgrade, Serbia

E-mail: rakonjacp@ptt.rs

Zoran MITROVIĆ, PhD, Full Professor

University of Novi Sad, Faculty of Technical Sciences,

Trg Dositeja Obradovića 6, 21000 Novi Sad, Serbia

E-mail: zoranmit@uns.ac.rs

Ivica MILANOVIĆ, PhD

Technical Test Center (TTC),

Vojvode Stepe 445A, 11000 Belgrade, Serbia

E-mail: msivica@gmail.com

Veljko NIKOLIĆ, MSc

Technical Test Center (TTC),

Vojvode Stepe 445A, 11000 Belgrade, Serbia

E-mail: veljkozmaj@yahoo.com

Zoran ILIĆ, PhD

Technical Test Center (TTC),

Vojvode Stepe 445A, 11000 Belgrade, Serbia

E-mail: zoranilic_65@yahoo.com

Nenko BRKLJAČ, PhD

Technical Test Center (TTC),

Vojvode Stepe 445A, 11000 Belgrade, Serbia

E-mail: brkljacnenko@gmail.com 